\title{
OS DIREITOS FUNDAMENTAIS NA CONSTITUIÇÃO BRASILEIRA
}

\author{
Dalmo de Abreu Dallari \\ Professor Titular do Departamento de Direito do Estado \\ da Faculdade de Direito da Universidade de São Paulo
}

Resumo:

A sociedade brasileira vem revelando, na últimas décadas, o crescimento de novas forças sociais, nascidas na luta contra as ditaduras militares e influenciadas pelo consenso mundial de que os direitos humanos devem ser os princípios fundamentais de uma sociedade harmônica e justa.

Apesar disso, ao lado dos novos fatores de influência a Constituição brasileira revela a permanência parcial de uma herança colonial negativa, com a dominação de elites conservadoras e reacionárias. A nova década deverá assistir à superação dessa contradição.

Abstract:

The brazilian society is revealing, in the last decades, the growing of new social forces born in the figthing against military dictatorship and influenced by the world conviction that human rights must be the fundamental principles of a just and harmonic society.

Notwithstanding, besides these new infuential factors, the constitutional frame of the country shows clearly the partial permanence of the negative colonial heritage, as the domination of conservatives and reactionaries elites, including old fashioned land-owners, impresarios, politicians and intelectuals.

That contradiction can be detected in the brazilian Constitution of 1988. The most democratic in the constitutional history of the country, in terms of people's participation, incorporating new fundamental rights and guaranties, the some Constitution assures the permanence of a discriminatory social and economic order. The next decade must know the overcoming of that contradiction.

1. Direitos Fundamentais no Brasil: uma injustiça histórica.

Existem no Brasil tantas situações de marginalização e de injustiça social, e isso aparece com tamanha evidência, que se tem a impressão de que nada de positivo pode ser dito relativamente à situação dos Direitos Humanos. 
Na realidade, desde o início da colonização do território brasileiro pelos portugueses, no ano de 1500 , foi estabelecida no Brasil uma sociedade profundamente marcada pela diferenciação entre os novos senhores da terra e os outros. As primeiras vítimas dessa nova sociedade foram os índios, primitivos habitantes da terra brasileira, que o colonizador explorou de várias formas, tentando escravizá-los e roubando suas terras. Acostumado a viver em liberdade, em relação íntima com a natureza, o índio tentou resistir, mas a superioridade de armas e a ambição de riqueza dos colonizadores foram mais fortes.

Calculam os historiadores que existiriam no Brasil, no ano de 1500, entre quatro e cinco milhões de índios. Mas eles foram sendo dizimados, ou pelas armas ou por falta do ambiente natural que garantia sua sobrevivência, conseguindo sobreviver apenas as comunidades mais protegidas pela floresta e poucos grupos isolados em alguns pontos do litoral.

Hoje restam menos de trezentos mil índios, muitos deles sendo vítimas da espoliação e das pressões da sociedade circundante. Empresários e agentes do governo se mostram impacientes e procuram apressar a eliminação dos grupos tribais remanescentes, considerados obstáculos à plena ocupação do território e à exploração das riquezas do solo e do subsolo.

$\mathrm{E}$ os índios vão morrendo de fome, porque os brancos estão destruindo as florestas e envenenando os rios, além de morrerem também de doenças levadas pelo branco, sem que o governo cumpra as obrigações legais de proteger os territórios indígenas e de proporcionar assistência médica aos índios. É um genocídio mais ou menos disfarçado, que necessita de algum tempo para se consumar, mas é absolutamente certo. Os "civilizados" estão assassinando os "selvagens".

A impossibilidade de escravizar os índios estimulou a escravidão de negros africanos, que começaram a chegar ao Brasil enviados pelos portugueses, que colonizaram também a África, desde o século XVI. A escravidão negra, tragédia humana que vitimava negros nascidos na África e no Brasil, durou até o ano de 1888, quando foi legalmente abolida. Com a abolição da escravatura o Brasil começou a receber grandes levas de trabalhadores europeus, contratados para trabalhar no campo.

Os negros libertados, sem dinheiro e sem preparação profissional, foram abandonados à sua própria sorte e passaram a constituir um segmento 
marginal da sociedade. Vivendo na miséria e, além disso, vítimas de um tratamento preconceituoso, passaram a trabalhar nas atividades mais rudimentares e com menor remuneração, o que arrastou muitos deles para a criminalidade, agravando ainda mais os preconceitos, embora estes sejam sempre negados.

Só muito recentemente, com a ampliação das oportunidades por influência da onda democratizante resultante da Segunda Guerra Mundial, começaram a cair as muralhas da marginalização. Os próprios negros foram tomando consciência das injustiças de que eram vítimas e começaram a se organizar para conquistar mais possibilidades de progresso social. $O$ aparecimento dos Estados africanos na década de sessenta, com populações negras, bem como a mobilização política dos negros nos Estados Unidos, exerceram grande influência sobre os negros brasileiros, que começaram a se organizar para a reivindicação do direito à igualdade.

Desde então vem aumentando o número de movimentos e associações de negros, muitos deles buscando recuperar seus vínculos culturais com a África, outros mais diretamente influenciados pelos movimentos negros norte-americanos e outros propondo-se, pura e simplesmente, a lutar por meios institucionais para modificar sua condição de brasileiros discriminados por motivo racial. A diversidade de inspirações e métodos impede a unificação desses grupos, que chegam mesmo, algumas vezes, a se hostilizar abertamente. É preciso assinalar também que, ao lado de uma resistência preconceituosa, existem muitas organizações defensoras de Direitos Humanos que denunciam a discriminação contra os negros e apóiam ostensivamente suas reivindicações.

Na prática os negros brasileiros, em sua grande maioria, continuam a pertencer às camadas mais pobres da população brasiieira. Entretanto, embora com evidente lentidão, os negros vão conquistando lugares nas universidades e nas profissões de mais alta qualificação. A presença do negro nos cargos de representação política também vai aumentando, mas tem contribuído muito pouco para a melhoria da condição social dos negros, pois vários dos eleitos para o Legislativo abandonaram a proposta de luta e preferiram fazer composições com as elites tradicionais, buscando vantagens pessoais.

É rnuito forte a presença negra nas áreas do esporte e da música popular, mas, nesses dois casos, aquele que revela melhores qualidades consegue 
prestígio social e derruba as barreiras do preconceito; daí porém só resultam benefícios de caráter pessoal, sem influir para melhorar a situação dos negros na sociedade brasileira.

Um dado significativo é a diminuição constante da porcentagem de negros na população brasileira, em conseqüência das imigrações européia e asiática, desde o final do século passado, como também em decorrência da miscigenação, sendo bem elevado no Brasil o número de mulatos, que é o resultado da união do negro e o branco. Cálculos mais recentes estimam que os negros representam hoje cerca de $6 \%$ da população brasileira.

A par desses segmentos socialmente inferiorizados, identificados por suas características étnicas e culturais, existem desníveis regionais e sociais muito acentuados no Brasil. Circunstâncias históricas aliadas a fatores políticos, com repercussões na economia, produziram um verdadeiro "arquipélago cultural", conforme a expressão de Alberto Torres, eminente sociólogo brasileiro da primeira metade do século XX.

As formas de ocupação do território, bem como a repercussão de acontecimentos políticos da Europa, além dos interesses econômicos europeus, tudo isso contribuiu para a definição de um tipo de sociedade em que desigualdade de direitos e de acesso à riqueza e aos benefícios proporcionados pela vida social é escandalosamente evidente. $O$ primeiro desnível profundo está na existência de uma parte pobre e atrasada, especialmente nas regiões norte e nordeste do país, ao lado de outra mais moderna e dinâmica, em que há muito mais oportunidades de trabalho e de ascensão social, englobando o sul e o centro-sul do país.

Nas regiões norte e nordeste prevalecem o latifúndio e as culturas extensivas e a organização política e social é semifeudal. Existe uma classe social dominante, que detém a propriedade da terra e, a partir dela, o controle do comando político e econômico. Com base numa aliança imoral, que perdura há mais de um século e meio, as lideranças nortistas e nordestinas garantem apoio político ao governo central. Em troca, o governo central fornece dinheiro, em forma de auxilios, ou de empréstimos que geralmente não são pagos pelos tomadores.

A par disso o governo da República também fornece serviços, mantendo organismos ditos de planejamento e de desenvolvimento ou de ajuda 
"às vítimas da seca". Assim a rara ocorrência de chuvas que caracteriza sobretudo a região nordeste gerou uma "indústria da seca". Trata-se de um canal permanente de concessão de auxílios, que nunca são usados para construir um bom sistema de irrigação e que jamais chegam até a população mais pobre. A par disso, o governo central concede financiamentos, em condições muito favoráveis, para a implantação de projetos agropecuários ou industriais que nunca saem do papel, sendo raros os empreendimentos concretizados.

Dentro desse mecanismo a presença do Estado é muito forte na região e os serviços públicos proporcionam mais empregos do que a iniciativa privada. E o acesso a tais empregos, assim como o uso dos serviços, depende sempre da concordância das elites dominantes, que assim aparecem como beneméritas e recebem em troca os votos agradecidos dos eleitores pobres, que são a maioria. Montou-se uma eficiente máquina de dominação política, econômica e social, que se completa com o aproveitamento malicioso do federalismo brasileiro e do sistema eleitoral e representativo do país. A dominação em muitos estados da Federação e a quantidade destes asseguram para essa região a maioria no Parlamento nacional, especialmente no Senado, onde todos os estados têm igual número de representantes.

$\mathrm{Na}$ região que compreende o sul e o centro-sul do Brasil houve uma evolução diferente desde o século XVIII. Sendo mais distante da Europa, essa região mereceu menos atenção nos primeiros séculos da colonização. Por esse motivo ela ficou mais atrasada, enquanto no nordeste se desenvolvia o plantio da cana-de-açúcar, que foi o primeiro produto brasileiro de exportação em grande escala.

Para ocupação do território brasileiro o governo português fez doações de grandes extensões de terras no século XVI. Esse foi o início do sistema de latifúndios e se constituiu na base a partir da qual se formaram as grandes famílias de proprietários. Os descendentes dos donatários ainda hoje dominam a região, controlando, inclusive, os meios de comunicação. Estes são utilizados para convencer a população pobre de que as lideranças regionais são competentes e lutam constantemente contra a pobreza, que dizem ser causada pela riqueza do sul.

A desvantagem inicial da parte sul do Brasil acabou sendo benéfica, pois deu possibilidade a outro tipo de exploração das riquezas, gerando uma elite. 
econômica que, embora também insensível às injustiças sociais, não procurou manter a pobreza e o atraso da população como base permanente de sua dominação. $\mathrm{O}$ desenvolvimento diferenciado já se faz presente no século XVIII, com a descoberta de ouro e pedras preciosas em Minas Gerais, uma província do centro-sul. Por ser uma região montanhosa essa parte do território não se prestava para culturas extensivas. A par disso, a atividade econômica baseada na mineração não exige a propriedade de grandes extensões de terra para produzir riqueza. Por isso não se teve aí o semifeudalismo estabelecido na parte norte do país.

E foi a partir dessa perspectiva que se desenvolveu a ocupação intensiva da região sul. Embora tenha havido plantio de cana-de-açúcar numa pequena parte do litoral do Rio de Janeiro, a ambição do ouro e das pedras preciosas acabou sendo determinante e inspirou a organização de grupos, chamados "entradas" ou "bandeiras", para avançar pelo território desconhecido em busca de riquezas.

Os "bandeirantes" saídos de São Paulo, que eram os integrantes das bandeiras, foram desbravando as matas e caminhando pelos rios, semeando cidades e fazendas. No extremo sul, caracterizado pela existência de extensas planícies, foi sendo intensificada a criação de gado, mas também sem a figura do donatário explorador da miséria e do atraso.

Durante o século XIX cresceram extraordinariamente as plantações de café, sobretudo na província de São Paulo, tendo sido amplamente utilizada a mão-de-obra escrava, de origem africana. Sem a perspectiva da quase auto-suficiência dos semifeudos do nordeste e tendo necessidade de trabalhar ativamente para formar e manter um patrimônio e para obter um alto nível de renda, os proprietários dessa região procuraram sempre agir com dinamismo e criatividade.

Esses modos de ocupação do território e de desenvolvimento econômico influíram bastante para a diferença de mentalidades entre o norte e o sul do Brasil, sendo uma das causas do profundo desnível econômico e da diferenciação cultural que hoje são patentes. Mas outros fatores foram sendo adicionados, merecendo especial referência a substituição da mão-de-obra escrava por trabalhadores livres, ocorrida a partir de 1888 , com a abolição da escravatura. 
Quando isso ocorreu, a parte norte do país já estava acomodada, a sociedade já havia atingido a estratificação, estando bem definida e consolidada a situação do pequeno número de proprietários dominadores e do restante, que era a grande parcela populacional de dominados. Por isso quase não havia escravos no norte e no nordeste e não houve necessidade de substituição da mãode-obra.

Na parte sul do país, especialmente em São Paulo, o número de escravos ainda era muito grande e para substituí-los foi iniciada a importação de trabalhadores livres europeus, com predominância de italianos, mas incluindo espanhóis, alemães e pequenos contingentes de outras nacionalidades. Um pouco mais tarde viria também um número significativo de japoneses.

$\mathrm{O}$ final do século XIX e o início do século XX foram muito marcantes na história brasileira. Uma das conseqüências da abolição da escravatura, formalizada em 1888, foi a derrubada da Monarquia e a implantação da República, em 1889. Com isso ficou enfraquecida a posição da antiga nobreza rural, naturalmente conservadora, criando-se ambiente favorável para as mentalidades mais progressistas.

Para muitos historiadores e estudiosos da vida econômica brasileira foi na passagem do século que se iniciou, verdadeiramente, a formação de um parque industrial no Brasil, com sua base principal em São Paulo. Muitos dos trabalhadores europeus chegados ao Brasil eram operários, emigrados da Europa como refugiados econômicos. Eles só haviam aceitado o trabalho rural por estarem vivendo com extrema dificuldade ou pela perspectiva de se tornarem proprietários de terras, porque se dizia que nesta parte do mundo havia terra de sobra à espera de ocupação.

Esses ficaram pouco tempo na agricultura e logo procuraram as cidades, levando para as indústrias nascentes sua experiência, mas também sua consciência de direitos e sua prática de reivindicação organizada. Logo vieram as associações operárias, antecessoras dos sindicatos, as reuniões políticas, os fundos de solidariedade e as greves.

Instala-se então no Brasil a luta clássica entre capital e trabalho, com as características da sociedade industrial. Os empregadores, viciados pela submissão forçada dos escravos e pela docilidade dos trabalhadores rurais brasileiros, reagiram com violência, tornando-se cọrrente a expressão: "a questão 
social é uma questão de polícia". Muitas das cenas de exploração e injustiça que marcaram tragicamente o início da revolução industrial européia se repetiram no Brasil até 1930.

A grande crise econômica de 1929, que abalou profundamente a Europa e os Estados Unidos, teve imediato reflexo no Brasil. As injustiças acumuladas, o desejo de modernização, a luta entre o campo e a indústria e, finalmente, a queda violenta dos preços do café no mercado internacional, tudo isso se conjugou e levou à deposição armada do presidente da República, Washington Luiz. Assim termina a primeira República e começa um novo período da história brasileira, com Getúlio Vargas assumindo a chefia de um governo provisório, que lhe daria condições para manobrar politicamente $\mathrm{e}$ permanecer à frente do governo brasileiro durante quinze anos ininterruptos.

Uma das principais características do período Vargas foi o desenvolvimento da legislação trabalhista, assegurando um mínimo de garantias aos trabalhadores. Entretanto, o aperfeiçoamento da legislação não representou, na prática, o efetivo respeito pelos direitos e a eliminação das injustiças. "Obter $o$ maior lucro possível pagando o menor salário possivel" continuou sendo o lema dos empresários. Sob influência dos Estados Unidos, com quem o Brasil se aliou na Segunda Guerra Mundial, toda reivindicação operária passou a ser classificada como "subversão comunista" e as Forças Armadas nacionais foram intensamente utilizadas para proteção da ordem, que era, na realidade, a ordem conveniente ao grande capital.

Entre 1960 e 1970 ocorreram profundas transformações na sociedade brasileira e certamente os historiadores irão falar dessa década como uma das mais importantes de toda a história brasileira. Em 1960 a maioria dos brasileiros morava no campo e em 1970 a população urbana já é maior do que a rural. As migrações de nordestinos para o sul do país, especialmente para o Rio de Janeiro e São Paulo, que já haviam aumentado depois de 1930, ganharam extraordinária intensidade. São Paulo é hoje a maior cidade nordestina do Brasil, pois aí vivem e trabalham cerca de três milhões de nordestinos, parte significativa do total de doze milhões de habitantes. Esses migrantes, em sua grande maioria, são pessoas modestas, sem qualificação profissional e, devido ao seu número elevado, não conseguiram habitações razoáveis, além de serem forçados a trabalhar nas atividades mais pesadas e com menor remuneração. Por 
isso estão concentrados nos bairros distantes da periferia ou moram em favelas, integrando a parte mais carente da população, de onde sai elevado número de crianças e adolescentes que vivem nas ruas em situação de marginalidade social.

Muito recentemente, como conseqüência imprevista dos governos militares que comandaram o Brasil entre 1964 e 1985, teve início uma importante mobilização social, iniciada nas camadas mais pobres, apoiadas pelos setores mais progressistas da Igreja Católica. Os primeiros grupos organizados foram denominados "comunidades eclesiais de base". Reunidos para a realização de trabalhos de interesse comum, como a construção de moradias rústicas, os membros dessas comunidades passaram a receber ensinamentos sobre a organização social e a respeito do uso de seus direitos. Assim adquiriram consciência política e mesmo sendo pobres passaram a influir sobre os governos, fazendo denúncias, apresentando reivindicações e cobrando dos políticos suas promessas eleitorais.

O exemplo dessas comunidades estimulou a formação de grande número de associações, para defesa de direitos, adoção de providências junto a autoridades, divulgação de situações de marginalidade e ofensas a Direitos Humanos. Deste modo surgiram inúmeros grupos organizados, dispostos a trabalhar sistematicamente para a eliminação das situações de injustiça e violência que envolvem milhões de brasileiros. Mas também foram formadas muitas associações voltadas para a promoção de interesses específicos de certos segmentos sociais, como as mulheres, os favelados, os negros, os índios, os aposentados, os deficientes físicos, etc. A partir da década de setenta esse movimento associativo chegou à classe média, intensificando-se a formação de entidades representativas de profissionais de mais alto nível. $\mathrm{O}$ exemplo mais expressivo desse movimento foi o aparecimento de associações de magistrados, com objetivos reivindicatórios.

Esse fenômeno associativo tem extraordinária importância, pois representa a superação do ultraindividualismo, tradicional na sociedade brasileira e razão da inexistência de pressões eficientes para a eliminação de privilégios injustos. Pode-se mesmo falar em "mudança qualitativa" da sociedade, estando em fase de superação o individualismo egoísta, para surgir em seu lugar uma convivência solidária, que já produziu efeitos políticos na Assembléia Nacional Constituinte que elaborou a Constituição de 1988. 
2. Promessas e negativas da nova Constituição.

Se fosse possível aplicar concretamente todos os capítulos e normas constitucionais favoráveis aos Direitos Humanos, sem a necessidade de considerar os aspectos econômicos, seria possível afirmar que a situação dos Direitos Humanos melhorou consideravelmente com a nova Constituição. Do mesmo modo, se houvesse a possibilidade de aplicar inteiramente as normas constitucionais relativas à ordem econômica, sem considerar os artigos que tratam dos Direitos Humanos e de suas garantias, a sociedade brasileira iria manter os privilégios e as injustiças sociais acumulados durante quase quinhentos anos de história.

Isso quer dizer que aparentemente existem duas orientações diferentes, dentro da própria Constituição, uma fortalecendo os Direitos Humanos e ampliando suas garantias e outra privilegiando os interesses econômicos. Mas o conflito é apenas aparente, pois no seu conjunto e a partir dos princípios expressamente estabelecidos a Constituição dá prioridade à pessoa humana e subordina as atividades econômicas privadas ao respeito pelos direitos fundamentais do indivíduo e à consideração do interesse social.

É evidente que a simples existência de uma nova Constituição, ainda que muito avançada, não é suficiente para que os Direitos Humanos sejam efetivamente respeitados e usados. Por vários motivos é previsível a ocorrência de dificuldades, mas sem dúvida alguma é melhor ter uma Constituição mais favorável à promoção e proteção da dignidade humana, pois a partir daí fica mais fácil a mobilização social de sentido democrático e humanista.

A nova Constituição brasileira fixa princípios, que deverão condicionar e orientar a aplicação de todas as suas normas, bem como as atividades legislativas, executivas e judiciárias. Esses princípios estão enunciados em diferentes artigos. O Título I se denomina "Dos Princípios Fundamentais" e aí se encontram no art. $4^{2}$, entre os princípios que regerão as atividades internacionais do Brasil, os seguintes: II. prevalência dos Direitos Humanos; VIII. repúdio ao terrorismo e ao racismo. No art. 170 estão expressos os princípios da ordem econômica, entre os quais se encontram a função social da propriedade e a redução das desigualdades sociais. 
Além desse expresso enunciado de princípios, encontram-se na Constituição outros parâmetros para interpretação e aplicação de suas normas, os quais são favoráveis aos Direitos Humanos. No próprio Título I estão expressos "a dignidade da pessoa humana" e "os valores sociais do trabalho e da livre iniciativa" como fundamentos do Estado brasileiro (art. 19, III e IV), que é definido como Estado Democrático de Direito (art. 1º, caput).

É significativa a inclusão no Título VIII da Constituição, referente à Ordem Social, de capítulos que cuidam "Da Seguridade Social", aí incluindo a assistência social, "Da família, da criança, do adolescente e do idoso" e "Dos indios". Este último capítulo tem especial significação, considerando-se que os índios constituem uma das minorias mais vulneráveis da sociedade brasileira, pois além de não estarem preparados para competir numa sociedade capitalista, muitos deles são analfabetos ou nem mesmo falam a língua portuguesa, que é o idioma do povo brasileiro.

A Constituição revela também certa preocupação com a igualdade de acesso aos serviços fundamentais prestados pela sociedade e pelo Estado, quando reconhece a saúde e a educação como "direito de todos e dever do Estado" (arts. 196 e 205). Considerando-se que grande parte da população é muito pobre e não tem meios econômicos para pagar pelos cuidados de saúde e pela educação, é importante o reconhecimento desses direitos, pois daí pode nascer a atribuição de responsabilidade às autoridades públicas.

O enunciado sistemático dos Direitos Humanos está no Título II da Constituição, que trata "Dos Direitos e Garantias Fundamentais". O capítulo I refere-se aos direitos e deveres individuais e coletivos, que são enumerados em setenta e sete incisos do art. 50, incluindo várias garantias formais. E no capítulo II, que vai do art. $6^{0}$ ao 11 , está a enumeração dos direitos sociais. Esses dois capítulos refletem, em muitos pontos, a influência dos Pactos de Direitos Humanos aprovados pela Organização das Naçôes Unidas em 1966, o Pacto de Direitos Civis e Políticos e o Pacto de Direitos Econômicos, Sociais e Culturais.

É interessante observar que essa influência foi indireta. $\mathrm{Na}$ realidade, o Brasil não ratificou até agora sua adesão aos Pactos de Direitos Humanos, mas através da Constituição de Portugal, que acolheu esses pactos e influiu sobre muitos constituintes brasileiros, os direitos civis, sociais e políticos, como proclamados pela ONU, acabaram chegando à Constituição brasileira. 
Os direitos políticos estão expressos nos arts. 14 a 16 . A leitura desses artigos revela que foram acolhidos os direitos considerados clássicos na democracia representativa característica do Estado liberal-burguês. As duas inovações mais significativas, em relação às anteriores Constituições brasileiras, foram a concessão do direito de voto aos analfabetos e aos maiores de dezesseis anos. Para os maiores de dezoito anos de ambos os sexos o voto é obrigatório, como já ocorria antes, e para os que tiverem entre dezesseis e dezoito anos o exercício desse direito é facultativo.

Um dado muito expressivo é a inexistência de um capítulo relativo aos direitos econômicos. $\mathrm{O}$ art. 170, que define os fundamentos da ordem econômica brasileira, tem a seguinte redação: " $A$ ordem econômica, fundada na valorização do trabalho humano e na livre iniciativa, tem por fim assegurar a todos existência digna, conforme os ditames da justiça social...' . Não há dúvida de que essa redação é bem expressiva e reflete uma posição teórica bastante avançada para uma sociedade capitalista. Mas é importante notar que se trata apenas de uma afirmação abstrata, que não foi complementada pela especificação de meios e garantias de caráter prático e objetivo.

É bem verdade que foram expressos como princípios de ordem econômica a função social da propriedade e a redução das desigualdades sociais. Mas ao mesmo tempo a Constituição manteve integralmente e sem restrições o direito de herança, por força do qual haverá brasileiros nascendo muito ricos ao lado de outros que já nascerão miseráveis, porque só herdarão a miséria dos seus pais. Assim também a garantia de lucro ilimitado para os empresários e manipuladores de capital, mais a garantia absoluta da propriedade, tornando praticamente inviáveis a reforma urbana e a reforma agrária, tudo isso torna certo que para mais da metade da população brasileira a pobreza continuará sendo um obstáculo ao uso dos direitos.

\section{Garantias formais e obstáculos práticos.}

Apesar da pobreza e do profundo desequilibrio social existem direitos fundamentais que poderão ser gozados por todos, ainda que com desigualdade. Entre esses há direitos referentes às relações de trabalho e outros relativos ao acesso aos serviços essenciais, sendo necessário um esforço 
constante para a garantia desses direitos a fim de que sejam gradativamente reduzidas as agressões à dignidade humana. Outros direitos são indispensáveis para que as próprias camadas mais pobres da população, com apoio de organizações sociais dedicadas aos Direitos Humanos, possam atuar politicamente e ter acesso aos meios judiciais de proteção, visando assegurar todos os direitos reconhecidos pela Constituição e reduzir as desigualdades.

De vários modos a Constituição procura assegurar o uso e a defesa dos direitos fundamentais. Assim, pelo $\S 2^{2}$ do art. $5^{2}$ ficou estabelecido que os direitos e garantias expressos na Constituição não excluem outros decorrentes do regime e dos princípios constitucionais, ou ainda de tratados internacionais de que o Brasil seja parte. Com base nessa regra poderá ser sustentada a existência de direitos implícitos, desde que não sejam contrários a alguma disposição constitucional.

É de extrema importância o § $1^{\mathrm{o}}$ do art. 5o, pelo qual "as normas definidoras dos direitos e garantias fundamentais têm aplicação imediata" $\mathrm{Na}$ Constituição de Portugal se encontra uma regra muito semelhante a essa, podendo-se dizer que desse modo se garante a aplicação imediata das normas da Constituição referentes a direitos e garantias fundamentais, sem necessidade de aguardar uma lei ordinária regulamentadora. Alguns autores se referem a essas normas como auto-aplicáveis, exatamente por não dependerem da edição de outras. $O$ importante é que essa inovação constitucional anula o argumento, muitas vezes utilizado por advogados e acolhido pelos tribunais, segundo o qual as normas constitucionais são apenas programáticas e dependem de regulamentação para serem aplicadas.

As garantias formais dos direitos estão contidas no art. 5o da Constituição, tendo sido reiteradas algumas que já constavam de Constituições anteriores, além de terem sido criados novos instrumentos de garantia.

Assim é que foi mantido o habeas-corpus, para garantia do direito de locomoção. Essa garantia já existe no direito positivo brasileiro desde 1832, tendo sido aperfeiçoada durante mais de um século e meio de experiência, sendo hoje amplamente utilizada, sobretudo para assegurar a liberdade em casos de prisão ilegal ou de sua ameaça.

O mandado de segurança é instrumento utilizado desde 1934, para suspender a aplicação de um ato ilegal de qualquer autoridade, que ofenda 
direito líquido e certo de uma pessoa física ou jurídica. Houve uma inovação nesse caso, pois a Constituição de 1988 criou o mandado de segurança coletivo, permitindo que um partido político, uma organização sindical, uma entidade de classe ou uma associação legalmente constituída defendam os direitos de seus membros. São duas garantias de objetivos semelhantes.

Outra inovação foi o habeas data, que permite a uma pessoa saber que informações constam a seu respeito em qualquer banco de dados de entidades governamentais ou de caráter público. Essa garantia foi inspirada na existência de registros sigilosos mantidos pelos organismos de segurança nacional, muitas vezes com dados errados ou falsos, sobre pessoas que faziam oposição aos governos militares.

Uma garantia nova, que vem sendo objeto de acesa polêmica, é o mandado de injunção, inspirado no direito norte-americano, mas tendo características próprias no Brasil. De acordo com a Constituição, será concedido mandado de injunção "sempre que a falta de norma regulamentadora tome inviável o exercício dos direitos e liberdades constitucionais e das prerrogativas inerentes à nacionalidade, à soberania $e$ à cidadania". Existe divergência doutrinária e jurisprudencial a respeito do objetivo do mandado de injunção. Muitos entendem que através dele pode-se obter do Judiciário a complementação da norma constitucional para um caso concreto que dependa dessa providência. Outros, porém, sustentam que ao conceder o mandado de injunção o juiz ou tribunal se limitará a comunicar ao órgão do Poder Legislativo competente, que este deve elaborar a norma complementar.

No Supremo Tribunal Federal, órgão máximo do Poder Judiciário, vem prevalecendo esta última interpretação, que é preferida pelos juízes de tendência conservadora. $\mathrm{O}$ argumento básico desses magistrados é que o juiz não pode transformar-se em legislador. Contra essa afirmação existe a lembrança de que ao conceder o mandado de injunção o juiz já dispõe de uma norma de direito positivo, que é o artigo da Constituição reconhecedor do direito ou da prerrogativa, devendo apenas complementá-lo para viabilizar a aplicação ao caso que lhe for submetido. Na prática, se prevalecer a interpretação mais restritiva estará anulado o mandado de injunção, pois a comunicação do juiz não garantirá que o Legislativo faça a lei, ou que a faça em tempo curto, nem impedirá que o 
Chefe do Executivo decida vetar o projeto que for aprovado pelo Legislativo, como permite a Constituição.

Além dessas garantias existe ainda a ação popular, que foi ampliada na Constituição de 1988, ganhando alcance bem maior do que tinha anteriormente. Por meio de ação popular qualquer cidadão é parte legítima para pedir ao juiz a anulação de ato lesivo ao patrimônio público ou de entidade de que o Estado participe. A inovação está na possibilidade de ação popular para anulação de atos que sejam lesivos à moralidade administrativa, ao meio ambiente e ao patrimônio histórico e cultural.

Finalmente, a Constituição prevê ainda o exercício dos direitos de petição e representação, que permitem a qualquer pessoa dirigir-se a uma autoridade, pedindo providências para a defesa de direitos ou contra ilegalidade ou abuso de poder.

Há vários aspectos do sistema de garantias que devem ser ressaltados. $\mathrm{O}$ primeiro deles é a atribuição de competências ao Poder Judiciário para efetivação das garantias. Embora sempre veementes na defesa de sua independência e de suas prerrogativas, muitos juízes temem o excesso de responsabilidade e chegam mesmo a dizer que a Constituição exagerou ao confiar todos esses encargos ao Judiciário.

Outro dado significativo é a atribuição de competências a associações para a defesa de direitos individuais. Além da legitimidade, já referida, para uso do mandado de segurança coletivo, diz a Constituição, no inciso XXI do art. 50, que "as entidades associativas, quando expressamente autorizadas, têm legitimidade para representar seus filiados judicial ou extrajudicialmente".

Esta última possibilidade deverá ganhar importância com o passar do tempo. As pessoas mais pobres não têm o hábito de utilizar o Poder Judiciário para defender seus direitos, ou por falta de informações, ou por não conseguirem o auxílio de um advogado ou ainda por terem medo de uma represália. $\mathrm{O}$ número de associações cresceu muito no Brasil nos últimos anos e por meio delas será mais fácil e menos perigoso chegar ao juiz para repelir uma agressão a direitos. 
4. Direitos Humanos no Brasil: entre o sonho e a realidade.

Com base no conjunto das situações e na realidade de agora podese dizer que os Direitos Humanos ainda não adquiriram existência real para grande número de brasileiros. A marginalização social é imensa e a discriminação econômica e social está apoiada na própria Constituição.

Entretanto, a sociedade brasileira está mudando, as camadas mais pobres da população estão adquirindo consciência de seus direitos e já conseguiram avançar muito no sentido de sua organização. A sociedade ultraindividualista, criada pelos colonizadores europeus e acentuada no século XX pela interferência norte-americana, está cedendo lugar a uma nova sociedade de indivíduos associados, que começam a descobrir a importância da solidariedade.

A utopia de um país de pessoas realmente livres, iguais em direitos e dignidade e com igualdade de oportunidades começou a despontar. As barreiras do egoísmo, da arrogância, da hipocrisia, da insensibilidade moral e da injustiça institucional, que até hoje protegeram os privilegiados, apresentam visíveis rachaduras. Já começou a nascer o Brasil de amanhã, que por vias pacíficas deverá transformar em realidade o sonho da justiça social, que muitos já ousam sonhar.

\section{BIBLIOGRAFIA}

ALMEIDA, Fernanda Dias Menezes de. Competências na Constituição de 1988. São Paulo : Atlas, 1991.

BARROSO, Luis Roberto. $O$ direito constitucional e a efetividade de suas normas. Rio de Janeiro : Renovar, 1990.

BENEVIDES, Maria Victória. A cidadania ativa. São Paulo : Ática, 1991.

BURSZTIN, Marcel. O poder dos donos. Petrópolis : Vozes, 1984.

COMPARATO, Fábio Konder. Para viver a democracia. São Paulo : Brasiliense, 1989.

COVRE, Maria de Lourdes (org.). A cidadania que não temos. São Paulo : Brasiliense, 1986. 
FERRAZ JR., Tércio Sampaio. Interpretaçāo e estudos da Constituição de 1988. São Paulo : Atlas, 1990.

PRUDENTE, Eunice Aparecida de Jesus. Preconceito racial e igualdade jurídica no Brasil. São Paulo : Julex, 1989.

SANTOS JR., Belisário dos et al. Direitos Humanos: um debate necessário. São Paulo : Brasiliense, 1988.

SILVA, José Afonso da. Curso de direito constitucional positivo. $5^{\underline{a}}$ ed. São Paulo : Revista dos Tribunais, 1989.

WHITAKER, Francisco et al. Cidadão constituinte. São Paulo : Paz e Terra, 1989. 